\title{
AQUARIUS AND THE AQUARIUS/SAC-D MISSION
}

\author{
D.M. Le Vine \\ NASA/Goddard Space Flight Center, 8800 Greenbelt Road, Greenbelt, MD 20771
}

G.S.E. Lagerloef

Earth and Space Research, 2101 Fourth Ave, Suite 1310, Seattle WA 98121

\author{
S. Torrusio \\ CONAE/Comision Nacional de Actividates Espaciales, Av. Paseo Colon 751, C1063ACH Buenos \\ Aires, Republica Argentina
}

\begin{abstract}
Aquarius is a combination L-band radiometer and scatterometer designed to map the salinity field at the ocean surface from space. It will be flown on the Aquarius/SACD mission, a partnership between the USA space agency (NASA) and Argentine space agency (CONAE). The mission is composed of two parts: (a) The Aquarius instrument being developed as part of NASA's Earth System Science Pathfinder (ESSP) program; and (b) SAC-D the fourth spacecraft service platform in the CONAE Satelite de Aplicaciones Cientificas (SAC) program. The primary focus of the mission is to monitor the seasonal and interannual variations of the salinity field in the open ocean. The mission also meets the needs of the Argentine space program for monitoring the environment and for hazard detection and includes several instruments related to these goals.
\end{abstract}

Index
Radiometry

\section{AQUARIUS}

The objective of Aquarius is to provide global maps of the surface salinity field with a spatial resolution of $150 \mathrm{~km}$ and accuracy of $0.2 \mathrm{psu}$ on a monthly basis. This is a challenging goal $(0.2$ psu corresponds roughly to $0.1 \mathrm{~K})$ and will require significant averaging $[2,4,10]$. To this end Aquarius has been designed to map the globe in 7 days with an exact repeat orbit. This is accomplished with three independent radiometers with a swath of about $320 \mathrm{~km}$ from an altitude is $657 \mathrm{~km}$ [5]. Each month this provides 4 samples near the equator and more in the cold waters of northern latitudes where the sensitivity is less [3].

Successful averaging requires a stable radiometer. The Aquarius radiometers are Dicke radiometers with an internal reference noise source based on a design developed in research at NASA's Goddard Space Flight Center and Jet Propulsion Laboratory [7, 9]. In addition, careful attention has been given to the thermal stability of the radiometers on the spacecraft. The sensitive elements in the radiometer front end will be controlled to within $0.1 \mathrm{C}$ over 7 days. As part of the design, active thermal control is provided for the front end and other elements of the system less sensitive to changes in gain (e.g. the radiometer backend and antenna feed horn), have been isolated from the front end [5]. Finally, extensive testing has been done to model the response of the radiometer to changes in temperature. The hardware includes temperature sensors and an algorithm has been developed using the test data to make a fine correction for changes in temperature [7].

Another element of the approach to meeting this remote sensing goal is to control as much as possible external sources of error. These include such things as radiation from the sun $[6,8]$, background radiation from the "sky" and atmosphere, and RFI. In this regard, Aquarius has some unique features: a) A co-located scatterometer to help provide a correction for roughness; b) A polarimetric radiometer channel (third Stokes parameter) to provide a correction for Faraday rotation; c) A sun-synchronous orbit with a $6 \mathrm{pm}$ (ascending) equatorial crossing to minimize Faraday rotation and to permit the antennas to look away from the sun toward the nighttime side of the terminator to minimize reflected radiation from the sun; d) An antenna designed to limit side lobes in the direction of both direct and reflected rays from the Sun; and e) Fast sampling to minimize data lost to RFI.

As part of calibration and to check stability, Aquarius will be rotated 180 degrees to look at cold sky. This will be done as often as monthly and at times and locations chosen to provide a stable "cold" reference (See Abraham et al, 2010 [1]). 


\section{SAC-D}

In addition to Aquarius, the observatory will include several instruments provided by CONAE and its partners. These instruments will be mounted on the SAC-D service platform. They include the New InfraRed Scanner Technology (NIRST) camera developed jointly by CONAE and Canadian Space Agency (CSA) to detect high temperature events such as forest fires and volcanoes, and a High Sensitivity Optical Camera (HSC) and a satellite Data Collection System being developed by CONAE. The Italian Space Agency (ASI) is providing a radio occultation experiment called, ROSA, and the French space agency, Centre National d'Études Spatiales (CNES), is providing a particle and radiation environment experiment called CARMEN I. A list of the instruments and summary of their objectives and specifications is given in Table I. Also among the instruments on the SAC-D is a microwave radiometer (MWR) being developed by CONAE. This consists of two pushbroom radiometers, one at $36.5 \mathrm{GHz}$ looking forward of the satellite ground track and one at 23.8 $\mathrm{GHz}$ looking aft. Each consists of 8 beams with a resolution of $50 \mathrm{~km}$ and arranged to cover the same swath as Aquarius. The spacecraft will yaw as it orbits so that the MWR and Aquarius footprints over lap. Although the MWR is a research development, among the possible applications is the potential for real time information on rain and perhaps wind speed to improve the Aquarius retrieval algorithm.

\section{THE OBSERVATORY}

Figure 1 is an artist's rendition of how the observatory will appear when complete. The collar at the interface between the SAC-D spacecraft bus and Aquarius is a shield for solar radiation that is part of the thermal control of Aquarius (it is not intended to be an RF shield). The spacecraft is oriented with nadir (earth viewing) downward and with the velocity vector into the figure. The sun is on the right, behind the solar panels. As mentioned above, the observatory is in a sunsynchronous orbit with equatorial crossings at 6 am and $6 \mathrm{pm}$ which keeps the ground track close to the day/night terminator and the Aquarius radiometer beams pointing toward the nighttime side

\section{STATUS}

Aquarius completed testing at the Jet Propulsion Laboratory in 2009 and currently is in Bariloche, Argentina, at the facilities of the CONAE prime contractor, INVAP, where the observatory is being assembled. Electrical interface testing was completed in February and mechanical integration of Aquarius with the SAC-D bus is scheduled for early March, 2010.

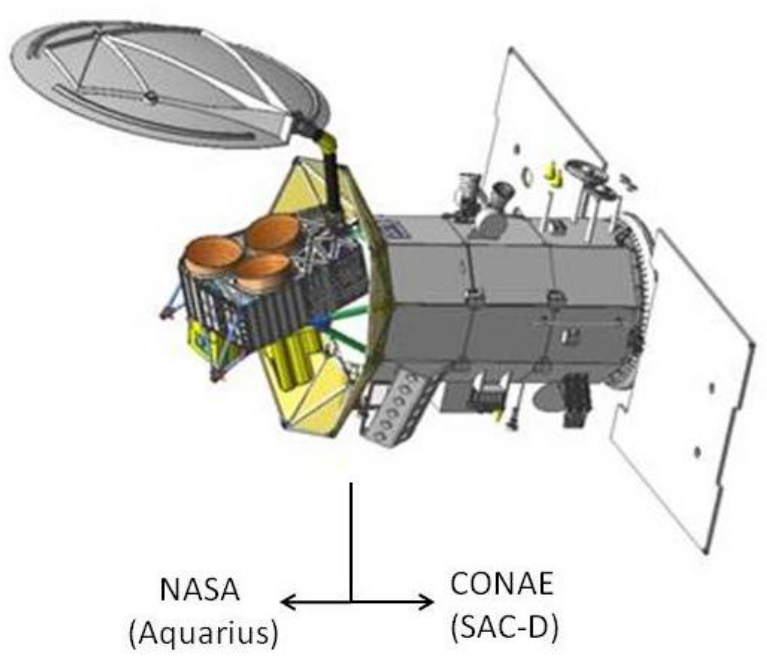

Fig 1. The Aquarius/SAC-D Observatory. The velocity vector is into the page, the sun is on the right and nadir (toward the Earth surface) is down.

Figure 2 shows Aquarius at JPL during the final stages of integration and testing. On the top is a view of Aquarius with the antenna in the deployed configuration taken during testing of the deployment mechanism. The three feed horns are also clearly visible in this image. To get an idea of the size, the reflector is $2.5 \mathrm{~m}$ in diameter. The black dots on the reflector are where the support posts mate while in the stowed configuration. On the bottom is a view of Aquarius in the stowed position taken while it was being prepared for shipment to Bariloche. One of the support posts is visible just above and to the left of the technician. The covers on the feed horns are for protection and will be removed before launch.

Figure 3 shows Aquarius during tests of the electrical interface with SAC-D in Bariloche in February, 2010. Aquarius is on the left of the photograph and SAC-D is to the right. The irregular shaped object on Aquarius over the feeds and behind the boom is a test target used for checking Aquarius operation.

After the observatory is assembled tests are completed (late spring, 2010), it will be sent to the Brazilian National Institute for Space Research (INPE) facility in Sao Jose dos Campos for environmental testing. When environmental testing is complete, the observatory will be shipped from Brazil back to California for launch from Vandenberg AFB. As of the writing of this paper, the final launch was still being negotiated, but the goal is for a launch in December, 2010. 


\section{REFERENCES}

[1] Abraham, S, D.M. Le Vine and E.D. Dinnat, "Background Emissions during Cold Sky Calibration of Aquarius", Proc. MicroRad 2010, Washington, D.C., March 1-4, 2010.

[2] Font, J., G.S.E. Lagerloef, D.M. Le Vine, A. Camps andQ-Z. Zanife, "The Determination of Surface Salinity with the European SMOS Space Mission", IEEE Trans. Geoscience and Remote Sensing, Vol 42 (\#10), pp 2196-2205, October, 2004.

[3] Lagerloef, G.S.E., F.R. Coulomb, D. Le Vine, F. Wentz, S. Yueh, C. Ruf, J. Lilly, J. Gunn, Y. Chao, A. deCharon, G. Feldman and C. Swift, "The Aquarius/SAC-D Mission": Designed to Meet the Salinity Remote-Sensing Challenge", Oceanography Magazine, Vol 21 (\#1), pp 68-81, March, 2008.
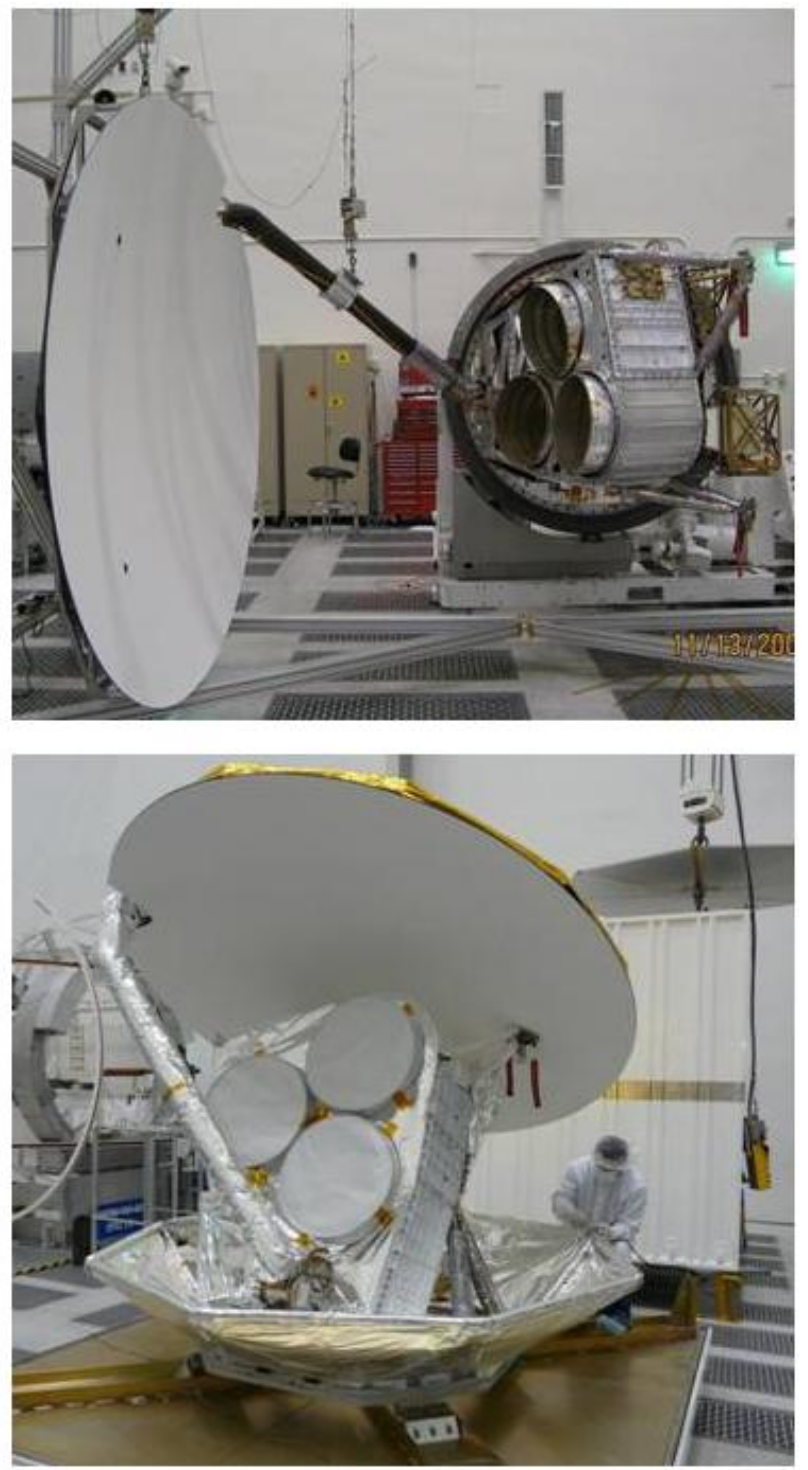

Fig 2. Aquarius during I\&T at JPL. Deployed configuration (top) and stowed configuration (bottom).
[4] Le Vine, D.M., G.S.E. Lagerloef, S.E. Torrusio, "Aquarius and Remote Sensing of Sea Surface Salinity from Space", Proc. IEEE, scheduled for publication, 2010.

[5] Le Vine, D.M., G.S.E. Lagerloef, F. R. Colomb, S. H. Yueh, F.A. Pellerano, "Aquarius: An Instrument to Monitor Sea Surface Salinity from Space", IEEE Trans. Geoscience and Remote Sensing, Vol 45 (\#7), pp. 2040-2050, July, 2007.

[6] Le Vine, D.M., S. Abraham, F. Wentz and G.S.E. Lagerloef, "Impact of the Sun on Remote Sensing of Sea Surface Salinity from Space" Proc. IGARSS, Seoul Korea, July, 2005, Vol 1, pp 288-291, doi: 10.1109/IGARSS.2005.1526164.

[7] Pellerano, F.A., J. Piepmeier, M. Triesky, K. HOrgan, J. Forgione, J. Caldwell, W.J. Wilson, S. Yueh, M. Spencer, D. McWatters and A. Freedman, "The Aquarius Ocean Salinity Mission High Stability L-band Radiometer", Proc. IGARSS'06, July 31-Aug 4, 2006, pp 1681-1684.

[8] Reul, N., J. Tenerelli, B. Chapron and P. Waldteufel, "Modeling Sun Glitter at L-band for Sea Surface Salinity Remote Sensnig with SMoS", IEEE Trans. Geoscience and Remote Sensing, Vol 45 (\#7), pp. 2073-2087, July, 2007.

[9] Wilson, W.J., A. Tanner, F. Pellerano and K. Horgan, "Ultrastable Radiometers for Future Sea Surface Salinity Missions", Jet Propulsion Laboratory internal Report, D-31794, April, 2005

[10] Yueh, S.H., R. West, W.J. Wilson, F.K. Li, E.G. Njoku and Y. rahmat-Sami, "Error Sources and Feasibility for Microwave Remote Sensing of Ocean Surface Salinity", IEEE Tran. Geoscience and Remote Sensing, Vol 39 (\#5), pp 1049-1059, May, 2001.

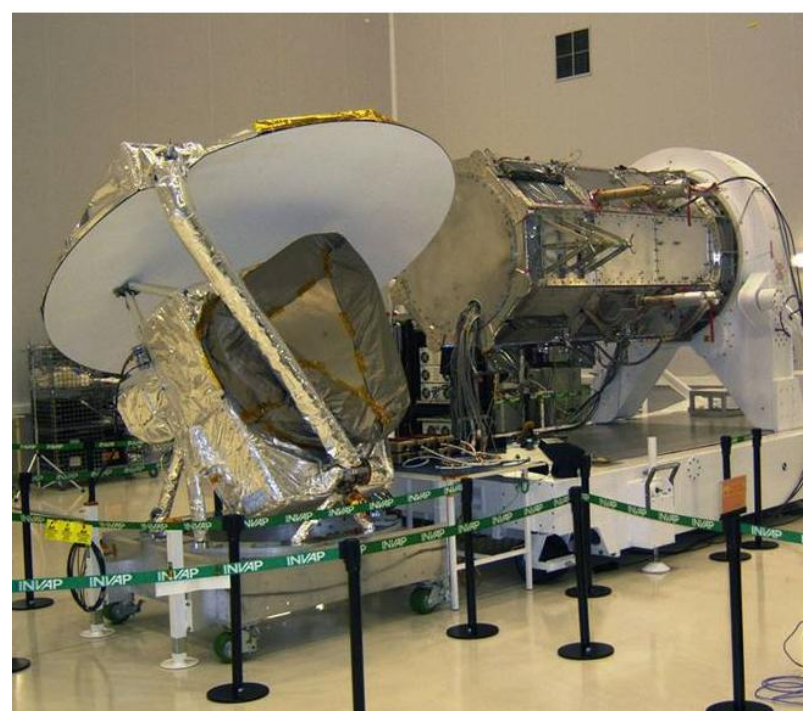

Fig 3: Aquarius (left) and the SAC-D spacecraft bus (right) during tests of the electrical interface at INVAP in Bariloche, Argentina. 


\section{Table I: Aquarius/SAC-D Instruments}

\begin{tabular}{|c|c|c|c|c|}
\hline INSTRUMENT & OBJECTIVES & SPECIFICATIONS & RESOLUTION & AGENCY \\
\hline $\begin{array}{l}\text { Aquarius } \\
\text { Radiometer } \\
\text { \& Scaterometer }\end{array}$ & $\begin{array}{c}\text { Sea Surface Salinity } \\
\text { Soil Moisture }\end{array}$ & $\begin{array}{c}\text { Integrated L- Band Radiometer } \\
\text { (1.413 Ghz) \& } \\
\text { Scatterometer (1.26 Ghz) } \\
\text { Swath: } 390 \mathrm{~km}\end{array}$ & $\begin{array}{l}\text { Three beams: } 76 \times 94 \\
84 \times 120,96 \times 156 \mathrm{~km}\end{array}$ & NASA \\
\hline $\begin{array}{l}\text { MWR } \\
\text { Microwave } \\
\text { Radiometer }\end{array}$ & $\begin{array}{l}\text { Precipitation, wind } \\
\text { speed, } \\
\text { sea ice concentration }\end{array}$ & $\begin{array}{c}\text { Bands: } 23.8 \mathrm{Ghz} \vee \mathrm{Pol} \text {. and } \\
36.5 \mathrm{Ghz} \mathrm{H} \text { and } \vee \text { Pol. } \\
\text { Band width: } 0.5 \text { and } 1 \mathrm{Ghz} \\
\text { swath: } 380 \mathrm{~km}\end{array}$ & $\begin{array}{c}\text { Sixteen beams } \\
<54 \mathrm{~km}\end{array}$ & ONAE \\
\hline $\begin{array}{c}\text { NIRST } \\
\text { New Infrared } \\
\text { Sensor Technology }\end{array}$ & $\begin{array}{l}\text { Hot spot events. } \\
\text { sea surface temperature } \\
\text { measurements }\end{array}$ & $\begin{array}{c}\text { Bands: } 4,11 \text { y } 12 \mathrm{um} \\
\text { Instantaneous swath } 182 \mathrm{Km} \\
\text { extended swath } 1000 \mathrm{Km} \\
\text { Pointing: } \pm 30^{\circ}\end{array}$ & $\begin{array}{c}\text { Space resolution: } 350 \mathrm{~m} \\
\text { in temperature: } 0.5^{\circ} \mathrm{C} \\
\text { smallest burning detectable } \\
\text { area } \\
200 \mathrm{~m}^{2}\end{array}$ & $\begin{array}{l}\text { CONAE } \\
\text { CSA }\end{array}$ \\
\hline $\begin{array}{c}\text { HSC } \\
\text { High Sensitivity } \\
\text { Camera }\end{array}$ & $\begin{array}{l}\text { Urban lights, electric storms, } \\
\text { polar regions, } \\
\text { snow cover, ships detection }\end{array}$ & $\begin{array}{l}\text { Pancromatic: } 450-600 \mathrm{~nm} \\
\text { Swath: } 700 \mathrm{Km}\end{array}$ & 200-300 meters & CONAE \\
\hline $\begin{array}{c}\text { DCS } \\
\text { Data Collection } \\
\text { System }\end{array}$ & Data Collection System & 401.55 Mhz uplink & $\begin{array}{l}2 \text { contacts per day } \\
\text { with } 200 \text { platforms }\end{array}$ & CONAE \\
\hline \multirow[t]{2}{*}{$\begin{array}{c}\text { ROSA } \\
\text { Radio Occultation } \\
\text { Sounder for Atmosphere }\end{array}$} & Atmospheric properties & GPS Occultation Techniques & Horiz: $300 \mathrm{Km}$ Vert: $300 \mathrm{~m}$ & ASI \\
\hline & $\begin{array}{c}\text { Effects of cosmic radiation } \\
\text { in electronic devices, } \\
\text { distribution of micro-particles } \\
\text { and space debris }\end{array}$ & $\begin{array}{l}\text { I: three Si detectors, Si/Li } \\
\text { S: four MOS sensors }\end{array}$ & $\begin{array}{l}\text { 1: } 256 \text { channels spectra } \\
\text { S: Sensitivity: } 0.5 \text { u part. } \\
\text { at } 10 \mathrm{Kkm} / \mathrm{sec}\end{array}$ & CNES \\
\hline $\begin{array}{l}\text { TDP } \\
\text { Tech. Demonstration } \\
\text { Package }\end{array}$ & $\begin{array}{l}\text { Position, velocity and time } \\
\text { inertial angular velocity } \\
\text { determination }\end{array}$ & $\begin{array}{c}\text { GPS receiver } \\
\text { Inertial Unit Reference }\end{array}$ & $\begin{array}{c}\text { Position: } 20 \mathrm{~m} \text {, velocity: } 1 \mathrm{~m} / \mathrm{sec} \\
\text { Angular Random Walk: } \\
0.008 \mathrm{deg} / \mathrm{sqr} \mathrm{h}\end{array}$ & CONAE \\
\hline
\end{tabular}

